\title{
Dynamic Thiol/Disulfide Homeostasis In Patients With Autoimmune Subclinical Hypothyroidism
}

Ihsan Ates ${ }^{1}$, Mustafa Altay ${ }^{1}$, Fatma Meric Y1lmaz ${ }^{2,3}$, Canan Topcuoglu ${ }^{2}$, Salim Neselıoglu ${ }^{3}$, Ozcan Erel $^{3}$, Nisbet Y1lmaz $^{1}$

${ }^{1}$ Ankara Numune Education and Research Hospital, Department of Internal Medicine, Ankara, Turkey

${ }^{2}$ Ankara Numune Education and Research Hospital, Department of Biochemistry, Ankara, Turkey

${ }^{3}$ Yıldırım Beyazıt University Medical Faculty, Department of Biochemistry, Ankara, Turkey

\section{Objectives:}

\section{Methods:}

\section{Results:}

Table 1. Levels of thiol/disulphide homeostasis parameters betw een groups

Abnormal thiol/disulphide homeostasis has been shown to be responsible for a number of diseases in which chronic inflammation is predominant. However, the role of thiol/disulphide homeostasis in the pathogenesis of Hashimoto thyroiditis, which is also a chronic inflammatory disorder, is not known. In this study, we aimed to investigate dynamic thiol/disulphide homeostasis in patients with subclinical hypothyroidism using the new and automatic method developed by Erel \& Neselioglu.

Fourty eight patients with newly diagnosed subclinical hypothyroidism due to Hashimoto thyroiditis and not yet on any treatment and 48 healthy subjects without any known disease were enrolled. Thiol/disulfide homeostasis [native thiol(-SH) -disulphide(-S-S-) exchanges] was measured in both groups with new method developed by Erel and Neselioglu. The half of the difference between total thiol (-SH + -S-S-) and -SH concentrations gave the -S-S- bond amount.

\begin{tabular}{|c|c|c|c|}
\hline Variables & $\begin{array}{c}\text { Confrol } \\
(n=48)\end{array}$ & $\begin{array}{c}\text { Subclinical } \\
\text { Hypothy roidisim } \\
(\mathrm{n}=48)\end{array}$ & $\mathbf{p}$ \\
\hline$-\mathrm{SH}(\mu \mathrm{mol} / \mathrm{L})$ & $398 \pm 49.8$ & $375.1 \pm 38.7$ & $0.014^{4}$ \\
\hline$-\mathrm{SH}+-\mathrm{S}-\mathrm{S}-(\mu \mathrm{mol} / \mathrm{L})$ & $432.4 \pm 51.3$ & $416.7 \pm 40.9$ & 0.101 \\
\hline$-\mathrm{S}-\mathrm{S}-(\mu \mathrm{mol} / \mathrm{L})$ & $17.2 \pm 6$ & $20.8 \pm 6$ & $0.004^{4}$ \\
\hline$-\mathrm{S}-\mathrm{S}-\mathrm{-SH}(\%)$ & $4.4 \pm 1.7$ & $5.6 \pm 1.7$ & $0.001^{*}$ \\
\hline$-\mathrm{S}-\mathrm{S}-(-\mathrm{SH}+-\mathrm{S}-\mathrm{S}-)(\%)$ & $4 \pm 1.4$ & $5 \pm 1.4$ & $0.001^{*}$ \\
\hline$-\mathrm{SH} /(-\mathrm{SH}+-\mathrm{S}-\mathrm{S}-)(\%)$ & $92 \pm 2.8$ & $90 \pm 2.7$ & $0.001 \%$ \\
\hline
\end{tabular}

In patients with subclinical hypothyroidism, $-\mathrm{SH}$ level and $-\mathrm{SH} /(-\mathrm{SH}+-\mathrm{S}-\mathrm{S}-)$ ratio was found to be lower than that of the control group. $-S-S-$ level $(p=0.004),-S-S-/-S H(p=0.001)$ and $-S-S-/(-S H+-S-$ $S-)(p=0.001)$ ratio was higher in patients with subclinical hypothyroidism as compared to that of the control group. A positive correlation was found between anti-TPO and anti-Tg levels and $-\mathrm{S}-\mathrm{S}-/-\mathrm{SH}$ ve $-\mathrm{S}-\mathrm{S}-/(-\mathrm{SH}+-\mathrm{S}-\mathrm{S}-)$ levels while a negative correlation was found with $-\mathrm{SH} /(-\mathrm{SH}+-\mathrm{S}-\mathrm{S}-)$ level.

Thiol/disulfide homeostasis was found to have a tendency towards -S-S- formation in patients with subclinical hypothyroidism and thyroid autoantibodies were correlated positively with thiol oxidation. Abnormal thiol/disulfide homeostasis in patients with Hashimoto thyroiditis, is whether a cause or a consequence, may be illustrated by using thiol-containing drugs and following autoantibody levels. The efficacy, dose and duration of thiol drugs may be monitored easily, effectively, quickly and cheaply by the method developed by Erel and Neselioglu.

\section{References:}

1. Erel, O. and S. Neselioglu, A novel and automated assay for thiol/disulphide homeostasis. Clin Biochem, 2014. 47(18): p. 326-32. 2. Hollowell JG, Staehling NW, Flanders WD, Hannon WH, Gunter EW, Spencer CA, et al. (2002) Serum TSH, T(4), and thyroid antibodies in the United States population (1988 to 1994): National Health and Nutrition Examination Survey (NHANES III). J Clin Endocrinol Metab 87, 489-499.

3. Weetman AP (2004) Cellular immune responses in autoimmune thyroid disease. Clin Endocrinol (Oxf) 61, 405-413. 